degeneration of the anterior horn cells. Its absence in the severe infantile forms of the disease suggests that fasciculation of somatic muscles is uncommon in this form. Buchthal and Olsen ${ }^{5}$ found fasciculation in only 2 of 30 patients with infantile SMA but in half of 61 patients with the juvenile form culled from reports. Hausmanowa-Petrusewicz et $a l^{6}{ }^{6}$ found fasciculation in $10 \%$ of muscle samples of type Ia SMA (acute early infantile) compared with about $40 \%$ in type III (Kugelberg-Welander) type of SMA.

It is of interest that of two sisters with KugelbergWelander syndrome the elder (aged 32 years) showed neither ECG nor hand tremor; the younger sister aged 18 years showed a marked hand and ECG tremor. This suggests that the elder sister may have reached the 'burnt out' stage of the disease while in the younger it was still active. Serial ECGs were not done in any of our patients and this would be of interest in understanding the development of the disease. The close correlation between clinical tremor of the hands and ECG tremor with the type of SMA suggests that the clinical tremor is due to fasciculation of the forearm muscles. However, the presence of ECG tremor in the absence of hand tremor and vice versa indicates that fasciculation detected by ECG does not necessarily emanate from the same muscles causing the hand tremor.

Tongue fasciculation was found in $60 \%$ of our patients and this is in accordance with the experience of others. ${ }^{78}$ Its presence in a floppy infant with symmetric proximal muscle weakness is diagnostic of

\section{Effects of smoking on breast feeding}

\section{A J LYON}

\section{Cambridge Military Hospital, Aldershot}

SUMMARY Infant feeding methods used by mothers who smoke and by mothers who do not, who delivered in one maternity hospital, were compared to determine if smoking affected breast feeding. Significantly more of the smoking group chose either to bottle feed from delivery or, having been discharged from the hospital breast feeding, changed to bottle feeding before the baby was 6 weeks old. This pattern was seen in each socioeconomic group and, as the smoking and non-smoking mothers were otherwise comparable, suggests that smoking may have a direct effect on breast feeding.

Smoking during pregnancy is known to have an
SMA. We found the hand tremor and ECG tremor valuable in the diagnosis of the more benign forms of SMA. They were of no value in the severe infantile form of the disease

\section{References}

1 Moosa A, Dubowitz V. Spinal muscular atrophy in childhood: two clues to clinical diagnosis. Arch Dis Child 1973; 48: 386-8.

2 Russman B S, Fredericks E J. Use of the ECG in the diagnosis of childhood spinal muscular atrophy. Arch Neurol 1979; 36: 317-8.

3 Dubowitz V. Muscle disorders in childhood. Philadelphia: Saunders, 1978:148.

4 Thomas D J, Williams D O. Detection of somatic muscle fasciculation on electrocardiograms. $\mathrm{Br} \operatorname{Med} J$ 1976; i: 557-9.

5 Buchthal F, Olsen P Z. Electromyography and muscle biopsy in infantile spinal muscular atrophy. Brain 1970; 93: $15-30$.

6 Hausmanowa-Petrusewicz I, Fidziánska A, NiebrójDobosz J, Strugalska M H. Is Kugelberg-Welander spinal muscular atrophy a fetal defect? Muscle Nerve 1980; 3: 389-402.

7 Munsat T L, Woods R, Fowler W, Pearson C M. Neurogenic muscular atrophy of infancy with prolonged survival. Brain 1969; 92: 9-24.

8 Dubowitz V. Infantile muscular atrophy. A prospective study with particular reference to a slowly progressive variety. Brain 1964; 87: 707-18.

Correspondence to $\mathrm{Dr}$ A A Dawood, Department of Paediatrics and Child Health, Faculty of Medicine, PO Box 17039, Congella 4013, South Africa.

Received 25 November 1982

adverse effect on the fetus. Infants born to mothers who smoke in pregnancy have a lower mean birthweight and higher neonatal mortality compared with those born to non-smokers. ${ }^{12}$ Little is known about the effects of smoking, in the puerperium, on lactation, and on the behaviour of the breast-fed infant. $^{34}$ The study reported here was carried out to determine if smoking has an effect on breast feeding.

\title{
Methods
}

The data were collected during a 3-month period in 1981 in a British military hospital in England. The hospital population was made up from service and local civilian mothers. 
During the study each mother was interviewed soon after delivery, her smoking history was recorded, and she was asked how she intended feeding her baby. The method of feeding on discharge from hospital and at 6 weeks postpartum was also recorded, the latter information being obtained either by telephone contact with the mother or from the health visitors.

Infants who required tube feeding-for example because of prematurity-were excluded.

The smoking group was made up from mothers who smoked during their pregnancy and continued to do so after delivery.

The smoking and non-smoking groups of mothers were compared for maternal age, parity, birthweight, and length of stay in hospital.

Three socioeconomic groups were defined, (1) social classes I and II plus officers; (2) social class III plus non-commissioned officers; and (3) social classes IV and V plus other ranks.

The methods of infant feeding of the smoking and non-smoking mothers at delivery, on discharge from hospital, and at 6 weeks postpartum were compared in each of these socioeconomic groups, using $\chi^{2}$ tests. Attempts were made to minimise any possible effect the study might have had on choice of feeding method. The proportion of mothers leaving hospital fully breast feeding was similar before, during, and after the study period.

Mothers did not know that they would be contacted again after discharge.

\section{Results}

Altogether 594 mothers were interviewed, $555(94 \%)$ being included in the study. Of these $186(33 \%)$ were smokers.

There were no statistically significant differences between the smoking and non-smoking groups when compared for maternal age, parity, or length of stay in hospital.

The mean birthweight of babies born to smokers was $3.25 \mathrm{~kg}$ and to non-smokers $3.40 \mathrm{~kg}(\mathrm{P}<0.01)$. Altogether 114 smokers and 277 non-smokers were discharged from hospital fully breast feeding. At 6 weeks postpartum $85(74.6 \%)$ smokers and 203 $(73.3 \%)$ non-smokers were contacted.

These 288 mothers were similar in age, parity, length of stay in hospital, and distribution of socioeconomic groups as were the 103 not contacted.

Table 1 shows the numbers of smoking and nonsmoking mothers who breast fed initially, on discharge from hospital, and at 6 weeks postpartum. The feeding methods of the smoking and nonsmoking mothers in each socioeconomic group are compared in Table 2.

Thirty $(69.8 \%)$ of the smoking and $22(55 \%)$ of the non-smoking mothers, who stopped breast feeding after discharge from hospital, gave their reasons for changing to bottle feeds. Of these, 18 $(60 \%)$ smoking and $11(50 \%)$ non-smoking mothers gave as their principal reason an inadequate milk supply or an unsettled baby.

Table 1 Mothers breast feeding initially, at discharge from hospital, and at 6 weeks postpartum according to maternal smoking history

\begin{tabular}{|c|c|c|c|c|c|c|c|}
\hline & \multicolumn{2}{|l|}{ Initial } & \multicolumn{2}{|c|}{ Discharge } & \multicolumn{2}{|c|}{ At 6 weeks } & \multirow{2}{*}{$\frac{\chi^{2} \text { trend }}{P}$} \\
\hline & No & $(\%)$ & No & $(\%)$ & No & $(\%)$ & \\
\hline $\begin{array}{l}\text { Smokers } \\
1-14 \text { cigarettes a day } \\
>15 \text { cigarettes a day } \\
\text { Non-smokers }\end{array}$ & $\begin{array}{l}94 / 118 \\
41 / 68 \\
318 / 369 \\
555\end{array}$ & $\begin{array}{l}(79 \cdot 7) \\
(60 \cdot 3) \\
(86 \cdot 2)\end{array}$ & $\begin{array}{l}79 / 118 \\
35 / 68 \\
277 / 369 \\
555\end{array}$ & $\begin{array}{l}(67 \cdot 0) \\
(51 \cdot 5) \\
(75 \cdot 1)\end{array}$ & $\begin{array}{l}32 / 62 \\
10 / 23 \\
163 / 203 \\
208^{*}\end{array}$ & $\begin{array}{l}(51 \cdot 6) \\
(43 \cdot 5) \\
(80 \cdot 3)\end{array}$ & $\begin{array}{l}<0.001 \\
<0.001 \\
<0.05\end{array}$ \\
\hline
\end{tabular}

* 288 of the 391 mothers breast feeding at discharge.

Table 2 Smoking and non-smoking mothers breast feeding initially, at discharge from hospital, and at 6 weeks postpartum according to socioeconomic group

\begin{tabular}{|c|c|c|c|c|c|c|c|c|c|c|c|c|c|}
\hline \multirow{3}{*}{$\begin{array}{l}\text { Socioeconomic } \\
\text { group }\end{array}$} & \multicolumn{4}{|l|}{ Initial } & \multicolumn{4}{|c|}{ Discharge } & \multicolumn{4}{|c|}{ At 6 weeks } & \multirow{3}{*}{$\frac{\chi^{2} \text { trend }}{P}$} \\
\hline & \multicolumn{2}{|c|}{ Smokers } & \multicolumn{2}{|c|}{ Non-smokers } & \multicolumn{2}{|c|}{ Smokers } & \multicolumn{2}{|c|}{ Non-smokers } & \multicolumn{2}{|c|}{ Smokers } & \multicolumn{2}{|c|}{ Non-smokers } & \\
\hline & No & $(\%)$ & No & $(\%)$ & No & $(\%)$ & No & $(\%)$ & $N o$ & $(\%)$ & No & $(\%)$ & \\
\hline $\begin{array}{l}\text { I, II } \\
\text { III } \\
\text { IV, V }\end{array}$ & $\begin{array}{l}31 / 35 \\
58 / 77 \\
46 / 75\end{array}$ & $\begin{array}{l}(88 \cdot 6) \\
(75 \cdot 3) \\
(62 \cdot 2)\end{array}$ & $\begin{array}{c}126 / 135 \\
136 / 165 \\
56 / 69\end{array}$ & $\begin{array}{l}(93 \cdot 3) \\
(82 \cdot 4) \\
(81 \cdot 2)\end{array}$ & $\begin{array}{l}29 / 35 \\
44 / 77 \\
38 / 74\end{array}$ & $\begin{array}{l}(82 \cdot 9) \\
(61 \cdot 0) \\
(51 \cdot 4)\end{array}$ & $\begin{array}{c}115 / 135 \\
116 / 165 \\
46 / 69\end{array}$ & $\begin{array}{l}(85 \cdot 2) \\
(70 \cdot 3) \\
(66 \cdot 7)\end{array}$ & $\begin{array}{c}16 / 23 \\
15 / 37 \\
11 / 25\end{array}$ & $\begin{array}{l}(69 \cdot 6) \\
(40 \cdot 5) \\
(44 \cdot 0)\end{array}$ & $\begin{array}{l}78 / 88 \\
64 / 88 \\
21 / 27\end{array}$ & $\begin{array}{l}(88 \cdot 6) \\
(72 \cdot 7) \\
(77 \cdot 8)\end{array}$ & $\begin{array}{l}<0.05 \\
<0.05 \\
<0.05\end{array}$ \\
\hline
\end{tabular}




\section{Discussion}

It seems from this study that mothers who smoke in pregnancy are less likely to choose to breast feed their babies. This may reflect the personality of a woman who has continued to smoke despite repeated antenatal advice to the contrary.

Considering only the mothers who wished to breast feed, there appears to be a relationship between smoking and failure to maintain breast feeding for 6 weeks. This relationship is more pronounced in the heavier smokers and is also seen within each socioeconomic group.

It appears, therefore, that independent of socioeconomic group, a woman who wants to breast feed will be more successful if she does not smoke. Support for this finding is reported in animal experiments which show that nicotine can reduce milk production. ${ }^{5}$ Nicotine is also excreted in breast milk ${ }^{6}$ but its effects on the newborn baby are not reported. It may be the cause of increased fretfulness which is interpreted as an unsettled baby due to underfeeding. The problem resolves when bottle feeding starts.

An inadequate milk supply and an unsettled baby are common reasons given for stopping breast feeding. ${ }^{7}$ In this study more of the smoking than the non-smoking mothers gave these as the reasons for changing to bottle feeds, but the difference was not statistically significant. More detailed investigation into the effect of smoking on lactation and infant behaviour are needed.

I thank Dr R O Walters, consultant paediatrician, for encouragement and advice, and the health visitors, Aldershot Area, for help in the collection of the data.

\section{References}

1 Butler N R, Goldstein H, Ross E M. Cigarette smoking in pregnancy: its influence on birth weight and perinatal mortality. Br Med J 1972; ii: 127-30.

2 D'Souza S W, Black P, Richards B. Smoking in pregnancy: association with skinfold thickness, maternal weight gain, and fetal size at birth. $\mathrm{Br} M e d J 1981 ; 282$ : 1661-3.

3 Whichelow M J. Breast feeding in Cambridge, England: factors affecting the mother's milk supply. J Adv Nursing $1979 ; 4: 253-61$.

4 Underwood P, Hester L L, Laffitte T, Jr, Gregg K V. The relationship of smoking to the outcome of pregnancy. Am J Obstet Gynecol 1965; 91 : 270-6.

5 Terkel J, Blake C A, Hoover V, Sawyer C H. Pup survival and prolactin levels in nicotine treated lactating rats. Proc Soc Exp Biol Med 1973; 143: 1131-5.

6 Ferguson B B, Wilson D J, Schaffner W. Determination of nicotine concentrations in human milk. Am J Dis Child 1976; 130: 837-9.

7 Starling J, Fergusson D M, Horwood L V, Taylor B. Breast feeding success and failure. Aust Paediatr J 1979; 15: $271-4$.

Correspondence to $\operatorname{Dr}$ A J Lyon, Department of Child Health, St George's Hospital, Blackshaw Road, London SW17 OQT.

Received 14 December 1982

\title{
Testicular feminisation syndrome presenting in the newborn
}

\author{
M SHERIDAN-PEREIRA AND NIALL O'BRIEN \\ Department of Paediatrics, National Maternity Hospital, Dublin
}

SUMMARY Testicular feminisation syndrome in a neonate was confirmed by cytogenetic studies. Karyotype analysis in 2 phenotypically female siblings showed the presence of the disorder in the 2 year old sibling. Subsequently a fourth phenotypically female sibling showed the disorder.

In general testicular feminisation syndrome presents in women because of primary amenorrhoea, or coincidentally at laparotomy, or as unilateral or bilateral inguinal masses that are male genital ducts and testes in a hernial sac. Inguinal hernia in prepubertal girls as an initial clinical sign of testicular feminisation syndrome is surprisingly rare. In a retrospective study ${ }^{1}$ on prepubertal girls $2.0 \%$ only of inguinal hernias were associated with the syndrome and none was found in a prospective study. ${ }^{2}$

In 1962 Gans and Rubin ${ }^{1}$ described the syndrome in a 13 day old infant with symptoms and signs of an incarcerated right inguinal hernia. In the absence of symptoms or family history, however, recognition in the newborn has not been previously described. Affected individuals generally appear normal at birth and throughout childhood. Identification of the syndrome among other family members is common.

\section{Case report}

In 1977 a phenotypically female infant weighing $3080 \mathrm{~g}$ at birth was noted on routine physical examination to have bilateral inguinal masses. A buccal 